\title{
Adoption and use of social media among public health departments
}

Rosemary Thackeray ${ }^{*}$, Brad L Neiger, Amanda K Smith and Sarah B Van Wagenen

\begin{abstract}
Background: Effective communication is a critical function within any public health system. Social media has enhanced communication between individuals and organizations and has the potential to augment public health communication. However, there is a lack of reported data on social media adoption within public health settings. The purposes of this study were to assess: 1) the extent to which state public health departments (SHDs) are using social media; 2) which social media applications are used most often; and 3) how often social media is used interactively to engage audiences.
\end{abstract}

Methods: This was a non-experimental, cross sectional study of SHD social media sites. Screen capture software Snag-It ${ }^{\circledR}$ was used to obtain screenshots of SHD social media sites across five applications. These sites were coded for social media presence, interactivity, reach, and topic.

Results: Sixty percent of SHDs reported using at least one social media application. Of these, $86.7 \%$ had a Twitter account, 56\% a Facebook account, and $43 \%$ a YouTube channel. There was a statistically significant difference between average population density and use of social media $(p=.01)$. On average, SHDs made one post per day on social media sites, and this was primarily to distribute information; there was very little interaction with audiences. SHDs have few followers or friends on their social media sites. The most common topics for posts and tweets related to staying healthy and diseases and conditions. Limitations include the absence of a standard by which social media metrics measure presence, reach, or interactivity; SHDs were only included if they had an institutionally maintained account; and the study was cross sectional.

Conclusions: Social media use by public health agencies is in the early adoption stage. However, the reach of social media is limited. SHDs are using social media as a channel to distribute information rather than capitalizing on the interactivity available to create conversations and engage with the audience. If public health agencies are to effectively use social media then they must develop a strategic communication plan that incorporates best practices for expanding reach and fostering interactivity and engagement.

\section{Background}

Social media has enhanced communication between individuals and organizations and it has the potential to augment public health communication. Social media refers to "activities, practices, and behaviors among communities of people who gather online to share information, knowledge, and opinions using conversational media" [1]. Social media applications are broadly categorized as forums and message boards, review and opinion sites, social networks, blogging and microblogging, bookmarking, and media sharing [2]. In particular, social

\footnotetext{
* Correspondence: rosemary_thackeray@byu.edu

Department of Health Science, Brigham Young University, 221 Richards Building, Provo, UT, USA
}

(c) 2012 Thackeray et al; licensee BioMed Central Ltd. This is an Open Access article distributed under the terms of the Creative Commons Attribution License (http://creativecommons.org/licenses/by/2.0), which permits unrestricted use, distribution, and reproduction in any medium, provided the original work is properly cited. media allows organizations to talk to their customers, to talk to the organization [3]. In public health, social media can be used to inform, educate, and empower people about health issues [4], to enhance the speed at which communication is sent and received during public health emergencies or outbreaks [5], to mobilize community partnerships and action [6], to facilitate behavior change [7], to collect surveillance data [8], and to understand public perceptions of issues [9].

Individual, corporate and organizational use of social media is increasing. It is estimated that by 2015 , the number of individuals and corporations who have social networking accounts will reach over three billion [10]. Sixty-five percent 
of adult internet users in the U.S. use social networking sites [11]. Technorati currently registers over 1.2 million blogs [12]. Thirteen percent of internet users have a Twitter account [13]. A study among Fortune 500 companies reported that $60 \%$ of corporations had Twitter accounts and 56\% had Facebook profiles [14]. Among Forbes 200 largest charities, use of at least one form of social media increased from $75 \%$ in 2007 to $97 \%$ in 2009 [15]. In public health, the Centers for Disease Control and Prevention is actively using social media [16]. However, there is a lack of data on social media adoption within broader public health settings, particularly state public health departments (SHDs).

A SHD baseline measure of social media adoption can serve as a benchmark for how public health agencies are doing at increasing access to health information through technology, an objective identified in Healthy People 2020 [17]. These data may act as a catalyst to accelerate social media use and encourage more research on the effectiveness of social media in public health. Therefore, the purposes of this study were threefold: 1) to assess the extent to which SHDs are using social media; 2) to determine which social media tools are used most often; and 3) to assess the extent to which social media is being used interactively to engage audiences.

\section{Methods}

This was a non-experimental, cross sectional study. We gathered SHD website URLs from the National Public
Health Information Coalition list [18]. We considered the SHD to be using social media if the website home page indicated an institutionally maintained account for at least one of five social media applications. SHDs were excluded if the social media application did not represent the entire SHD (e.g., Twitter account exclusively for flu response). We used screen capture software, Snag-It ${ }^{\circledR}$, to obtain screenshots of each social media homepage and related content for one month (February 2011 - March 2011). This software captures a screen image and archives it as an electronic file. Two researchers independently coded each of the screenshots for three areas: presence, interactivity, and reach (Table 1, Table 2). The post and tweet topics were categorized based on the classification scheme of the Centers for Disease Control and Prevention website homepage. Inter-rater coding agreement occurred 98.7\% of the time. Researchers resolved discrepancies by jointly reviewing the screenshot and re-coding the variable.

\section{Results}

Sixty percent $(\mathrm{n}=30)$ of SHDs were using social media. Twenty-two percent $(\mathrm{n}=11)$ of SHDs used one social media application and $22 \%(\mathrm{n}=11)$ used two, while $8 \%$ $(\mathrm{n}=4)$ were using three or four applications. Among SHDs using at least one social media application, $86.7 \%$ ( $\mathrm{n}=26)$ had a Twitter account, $56 \%$ had a Facebook account $(n=17), 43 \%(n=13)$ had a YouTube channel

Table 1 Fields included on the coding sheet

\begin{tabular}{|c|c|c|c|}
\hline Facebook & Twitter & YouTube & Flickr \\
\hline Facebook (FB) page URL & Twitter URL & Youtube URL & Flickr URL \\
\hline $\begin{array}{l}\text { Number of people who like the FB } \\
\text { page }\end{array}$ & $\begin{array}{l}\text { Number of tweets in one month \& total } \\
\text { all-time tweets }\end{array}$ & $\begin{array}{l}\text { Date YouTube channel was } \\
\text { established/joined }\end{array}$ & Date joined Flickr \\
\hline $\begin{array}{l}\text { FB Photos (yes/no) \& number of } \\
\text { photos }\end{array}$ & Number of Twitter followers & Number of YouTube upload views & $\begin{array}{l}\text { Number of photos in photo } \\
\text { stream }\end{array}$ \\
\hline Date of first/last FB wall post & $\begin{array}{l}\text { Number of Twitter users the state is } \\
\text { following }\end{array}$ & Number of YouTube subscribers & $\begin{array}{l}\text { Number of photo sets/photos } \\
\text { in each set }\end{array}$ \\
\hline $\begin{array}{l}\text { FB discussions (yes/no) \& number of } \\
\text { discussions }\end{array}$ & Date of the first/last tweet & $\begin{array}{l}\text { Number of YouTube channel } \\
\text { views }\end{array}$ & Number of photo set views \\
\hline $\begin{array}{l}\text { FB events (yes/no) \& number of } \\
\text { events }\end{array}$ & Total re-tweets & $\begin{array}{l}\text { Number of YouTube videos } \\
\text { posted }\end{array}$ & $\begin{array}{l}\text { Number of comments on each } \\
\text { photo set }\end{array}$ \\
\hline $\begin{array}{l}\text { FB videos (yes/no) \& number of } \\
\text { videos }\end{array}$ & Total @ symbols (replies or responses) & Name of YouTube video & Date of photo set \\
\hline Date of the individual FB wall post & Total hash-tag symbols & Date YouTube video was posted & \\
\hline Internal or external post (yes/no) & Post tweet via third-party API & Number of YouTube video views & \\
\hline Post an auto feed (yes/no) & & $\begin{array}{l}\text { Number of YouTube video likes/ } \\
\text { dislikes }\end{array}$ & \\
\hline FB post original (yes/no) & & $\begin{array}{l}\text { Number of YouTube video } \\
\text { comments }\end{array}$ & \\
\hline \multicolumn{4}{|l|}{$\begin{array}{l}\text { Total number of comments on FB } \\
\text { individual post }\end{array}$} \\
\hline $\begin{array}{l}\text { Total number of likes on FB } \\
\text { individual post }\end{array}$ & & & \\
\hline
\end{tabular}


Table 2 Metrics for coding state health department use of social media*

\begin{tabular}{|c|c|c|c|c|c|}
\hline Metric & Definition & Twitter metric & YouTube metric & Flickr metric & $\begin{array}{l}\text { Facebook } \\
\text { metric }\end{array}$ \\
\hline Presence & $\begin{array}{l}\text { existence of } \\
\text { particular social } \\
\text { media feature }\end{array}$ & number of tweets & $\begin{array}{l}\text { number of } \\
\text { videos }\end{array}$ & number of photos & $\begin{array}{l}\text { number of } \\
\text { posts, } \\
\text { videos, } \\
\text { views, } \\
\text { events, } \\
\text { discussions, } \\
\text { notes, \& } \\
\text { videos }\end{array}$ \\
\hline Interactivity & $\begin{array}{l}\text { audience members } \\
\text { posting content, comments, or likes }\end{array}$ & tweets, replies to tweets & $\begin{array}{l}\text { comments, } \\
\text { likes, dislikes }\end{array}$ & comments & $\begin{array}{l}\text { comments, } \\
\text { likes, } \\
\text { dislikes, } \\
\text { posts, replies } \\
\text { to posts, comments }\end{array}$ \\
\hline Reach & $\begin{array}{l}\text { number of people } \\
\text { the SHD connected } \\
\text { with through the } \\
\text { social media application }\end{array}$ & number of followers & number of subscribers & number of views & number of page likes \\
\hline
\end{tabular}

*Applications were selected for inclusion based on data obtained from Quantcast, Compete, and Alexa, that indicated these are the most commonly used within each social media category

and $13 \%(\mathrm{n}=4)$ had a Flickr account. Only one SHD had a blog. The reach of social media varied by each application (Table 3, Table 4, Table 5). The mean number of people who liked a SHD Facebook page was 789; SHDs had an average of 983 Twitter followers; the mean number of YouTube subscribers was 40 .

Posting on social media sites averaged once per day (Table 3, Table 4). Twitter re-tweets constituted $22.5 \%$ of all tweets; only $1.5 \%$ of tweets were in response to a tweet made by a follower. The SHD was the primary author of nearly all Facebook posts (89.5\%). Just over a quarter $(26.9 \%)$ of Facebook posts were an auto-feed, meaning that the content was originally posted on a third-party API (e.g., HootSweet). The majority (86\%) of Facebook posts received no comments and $45.1 \%$ of Facebook posts had no likes (Table 3).

Table 3 Facebook metrics associated with state health departments

\begin{tabular}{|c|c|c|c|c|c|c|c|c|c|}
\hline State & $\begin{array}{c}\text { Page } \\
\text { Established }\end{array}$ & $\begin{array}{l}\text { \# of } \\
\text { Page } \\
\text { Likes }\end{array}$ & $\begin{array}{l}\text { Total Posts in } \\
\text { one Month }\end{array}$ & $\begin{array}{l}\text { Posts with } \\
\text { Likesno (\%) }\end{array}$ & $\begin{array}{c}\text { Total } \\
\text { Likes } \\
\text { on } \\
\text { all } \\
\text { Posts }\end{array}$ & $\begin{array}{l}\text { Posts with } \\
\text { Commentsno. } \\
\text { (\%) }\end{array}$ & $\begin{array}{c}\text { Total } \\
\text { Comments on } \\
\text { Posts }\end{array}$ & $\begin{array}{l}\text { Ratio of Posts to } \\
\text { Comments }\end{array}$ & $\begin{array}{c}\text { Engagement } \\
\text { Rate* }^{*}\end{array}$ \\
\hline $\mathrm{AL}$ & $7 / 30 / 2009$ & 2227 & 93 & $67(72)$ & 117 & $8(9)$ & 19 & 11.63 & .066 \\
\hline AK & $6 / 1 / 2009$ & 1066 & 17 & $16(94)$ & 68 & $6(36)$ & 9 & 2.83 & .072 \\
\hline$A Z$ & $7 / 2 / 2009$ & 847 & 84 & 27 (32) & 56 & $7(8)$ & 11 & 12.00 & .067 \\
\hline$A R$ & $4 / 5 / 2010$ & 745 & 9 & $7(78)$ & 28 & $2(22)$ & 6 & 4.50 & .046 \\
\hline$C A$ & $6 / 29 / 2009$ & 1511 & 24 & $22(92)$ & 120 & $11(46)$ & 21 & 2.18 & .224 \\
\hline $\mathrm{CO}$ & $1 / 19 / 2010$ & 247 & 19 & $12(63)$ & 17 & $3(16)$ & 6 & 6.33 & .093 \\
\hline$C T$ & $6 / 25 / 2009$ & 557 & 54 & $7(13)$ & 9 & $1(2)$ & 1 & 54.00 & .018 \\
\hline $\mathrm{HI}$ & $3 / 30 / 2010$ & 132 & 15 & $2(13)$ & 3 & $0(0)$ & 0 & 0.0 & .023 \\
\hline LA & 10/1/2010 & 1179 & 63 & $46(73)$ & 101 & $14(22)$ & 40 & 4.50 & .111 \\
\hline $\mathrm{Ml}$ & $1 / 23 / 2009$ & 1993 & 23 & $14(61)$ & 41 & $3(13)$ & 6 & 7.67 & .024 \\
\hline MS & $10 / 20 / 2010$ & 76 & 2 & $1(50)$ & 1 & $1(50)$ & 2 & 2.00 & .039 \\
\hline NY & $8 / 11 / 2010$ & 432 & 30 & $21(70)$ & 61 & $4(13)$ & 10 & 7.50 & .164 \\
\hline $\mathrm{OH}$ & $11 / 16 / 2009$ & 678 & 16 & $12(75)$ & 20 & $2(13)$ & 5 & 8.00 & .037 \\
\hline $\mathrm{Rl}$ & $10 / 27 / 2010$ & 81 & 27 & $15(56)$ & 50 & $4(15)$ & 9 & 6.75 & .728 \\
\hline $\mathrm{TN}$ & $12 / 11 / 2009$ & 1289 & 9 & $3(33)$ & 7 & $1(11)$ & 2 & 9.00 & .007 \\
\hline VT & $12 / 2 / 2010$ & 120 & 6 & $2(33)$ & 3 & $0(0)$ & 0 & 0.0 & .025 \\
\hline WA & $7 / 22 / 2010$ & 231 & 15 & $3(20)$ & 5 & $2(13)$ & 4 & 7.50 & .039 \\
\hline
\end{tabular}

\footnotetext{
* Engagement rate $=$ likes + comments/number of page fans
} 
Table 4 Twitter metrics associated with state health departments

\begin{tabular}{|c|c|c|c|c|c|c|}
\hline State & Twitter & Twitter followers & All-time total tweets & Tweets in one month & @ Replies one month & Re-tweets in one month \\
\hline AK & $1 / 30 / 2009$ & 1404 & 778 & 43 & 0 & 22 \\
\hline$A Z$ & $3 / 24 / 2009$ & 2284 & 976 & 104 & 0 & 1 \\
\hline$A R$ & $5 / 9 / 2010$ & 181 & 36 & 4 & 0 & 0 \\
\hline$C A$ & $4 / 21 / 2009$ & 3039 & 802 & 43 & 0 & 2 \\
\hline $\mathrm{CT}$ & $4 / 27 / 2009$ & 1394 & 396 & 47 & 2 & 20 \\
\hline $\mathrm{DE}$ & $6 / 15 / 2009$ & 714 & 76 & 1 & 0 & 0 \\
\hline $\mathrm{HI}$ & 10/8/2009 & 1154 & 1572 & 159 & 7 & 120 \\
\hline IN & 8/9/2009 & 79 & 21 & 1 & 0 & 0 \\
\hline IA & 4/30/2009 & 2609 & 292 & 48 & 0 & 3 \\
\hline KS & $9 / 2 / 2009$ & 324 & 145 & 2 & 0 & 1 \\
\hline LA & 9/3/2010 & 759 & 553 & 63 & 3 & 13 \\
\hline MA & $4 / 12 / 2010$ & 1502 & 296 & 17 & 0 & 0 \\
\hline $\mathrm{Ml}$ & $7 / 16 / 2009$ & 1841 & 85 & 4 & 0 & 0 \\
\hline $\mathrm{MN}$ & $3 / 26 / 2009$ & 1238 & 445 & 3 & 0 & 0 \\
\hline MS & 10/3/2008 & 624 & 674 & 6 & 0 & 0 \\
\hline $\mathrm{MO}$ & 10/19/2009 & 70 & 42 & 4 & 0 & 1 \\
\hline $\mathrm{NH}$ & $5 / 21 / 2010$ & 73 & 8 & 8 & 0 & 0 \\
\hline NJ & 2/14/2011 & 172 & 151 & 17 & 1 & 0 \\
\hline NY & $4 / 8 / 2010$ & 467 & 253 & 12 & 0 & 0 \\
\hline $\mathrm{OH}$ & $11 / 16 / 2009$ & 1385 & 304 & 11 & 0 & 6 \\
\hline $\mathrm{Rl}$ & $4 / 25 / 2009$ & 218 & 33 & 14 & 0 & 0 \\
\hline SC & 1/4/2011 & 473 & 124 & 4 & 0 & 0 \\
\hline $\mathrm{TN}$ & $12 / 11 / 2009$ & 552 & 377 & 11 & 0 & 0 \\
\hline $\mathrm{VT}$ & $4 / 27 / 2009$ & 114 & 125 & 18 & 0 & 3 \\
\hline VA & 9/8/2010 & 1511 & 577 & 22 & 0 & 0 \\
\hline WA & $7 / 23 / 2009$ & 1367 & 2853 & 189 & 0 & 0 \\
\hline
\end{tabular}

The majority of Twitter tweets (79.7\%) were health related, $14.1 \%$ were non-health related, and for $6.2 \%$, the information was not adequate to determine the topic area. The health-related tweets focused on general areas of staying healthy (39.7\%), diseases and conditions
(26.2\%), environmental health (8\%), injury, violence, and safety (5.4\%), emergency preparedness and response (4.6\%), other diverse areas (16.1\%). Specifically, the most common topics were nutrition (11.4\%), heart disease (7.3\%), cancer $(7.3 \%)$, environmental health (6.5\%),

Table 5 YouTube metrics associated with state health departments

\begin{tabular}{|c|c|c|c|c|c|c|c|}
\hline State & Channel established & Number of subscribers & $\begin{array}{l}\text { Number } \\
\text { of videos }\end{array}$ & Uploaded views & $\begin{array}{l}\text { Videos } \\
\text { with } \\
\text { likes } \\
\text { no.(\%) }\end{array}$ & $\begin{array}{l}\text { Number } \\
\text { of likes }\end{array}$ & Number of comments \\
\hline$A L$ & $3 / 22 / 2010$ & 7 & 40 & 12144 & $2(5)$ & 5 & 10 \\
\hline$A Z$ & $4 / 21 / 2008$ & 282 & 146 & 24872 & $46(32)$ & 1100 & 22 \\
\hline$A R$ & $5 / 7 / 2010$ & 2 & 75 & 75 & $1(1)$ & 1 & 0 \\
\hline CA & $8 / 22 / 2008$ & 99 & 56 & 51142 & $9(16)$ & 23 & 4 \\
\hline $\mathrm{CO}$ & $8 / 16 / 2010$ & 2 & 15 & 1547 & $0(0)$ & 0 & 0 \\
\hline IN & $6 / 17 / 2010$ & 3 & 4 & 201 & $0(0)$ & 0 & 0 \\
\hline LA & $11 / 7 / 2010$ & 2 & 18 & 2362 & $3(17)$ & 7 & 1 \\
\hline $\mathrm{MO}$ & $10 / 14 / 2010$ & 12 & 32 & 7079 & $3(9)$ & 3 & 1 \\
\hline NY & $2 / 21 / 2007$ & 27 & 9 & 45259 & $8(88)$ & 32 & 7 \\
\hline NC & $7 / 1 / 2008$ & 38 & 50 & 31308 & $9(18)$ & 25 & 0 \\
\hline $\mathrm{OH}$ & 4/29/2009 & 4 & 6 & 554 & $1(17)$ & 1 & 0 \\
\hline $\mathrm{VT}$ & $1 / 14 / 2010$ & 4 & 14 & 1509 & $2(14)$ & 2 & 1 \\
\hline
\end{tabular}


tobacco use (6.5\%), flu, (5.4\%) and emergency preparedness and response (3.8\%).

The majority of Facebook posts $(88.3 \%)$ were healthrelated. Non-health posts had no common threads and included topics such as deaths of prominent officials, business awards, office hours, and job openings. Of the health-related posts, $77.8 \%$ were factual health-related information, $6.8 \%$ were about services offered, and $15.7 \%$ were event announcements. The most common topics were flu $(9.5 \%)$, environmental health $(6.0 \%)$, heart disease $(5.5 \%)$, nutrition $(4.5 \%)$, tobacco $(4.3 \%)$, emergency preparation (4.3\%), and cancer (3.6\%).

Views of photos and videos were limited. The total number of photos posted on Flickr was 167 (mean = 41.75). The ratio of views to photos ranged from 1.55 to 47.65. The mean number of You Tube videos was 30 . The mean number of video views was 687 (median = 144), not including an outlier CPR-related video receiving four million views. Over three-fourths of videos $(78.3 \%)$ received no likes and $70.7 \%$ of videos received no comments (Table 5).

Social media use differed between rural states and urban states. There was a statistically significant association between a SHD use of any social media and the U.S. Census Bureau's measure of the state's average population density per square mile $(r=.346 ; \mathrm{p}=.01)$. There were no significant differences between U.S. census region and use of social media (chi square $=2.279, \mathrm{p}=.517$ ) .

\section{Discussion}

The purpose of this study was to assess the degree to which SHDs were using social media and how they used it. The majority of SHDs are using at least one social media application with rates similar to large companies [14], charities [15], and nonprofit organizations [19]. However, compared to these organizations, a greater percentage of SHDs used Twitter. The overwhelming preference for Twitter may be associated with keeping the public up-to-date with SHD-related news. Yet Twitter is used by less than $13 \%$ of internet users [13], indicating a mismatch with audience preference for receiving information.

SHD's social media use varied by population density. These findings are in contrast to previous research that found no difference in individual use of social networking sites by urban or rural location [11]. The results are similar to a study that showed rural hospitals used social media less frequently than urban hospitals [20]. Additionally, on a typical day, people living in rural areas are less likely than urban residents to visit a video sharing site [21] and only $9 \%$ of Twitter users live in rural areas [22].

Audience reach with social media was limited. Relative to a state's population, the proportion of people who comprised followers, friends, and subscribers was small.
An audience member's demographic characteristics, including occupation or professional affiliations, are unknown on social media applications. It is possible that the audience is the general population, or other public health professionals, including SHD employees.

Social media is more than another communication channel. As mentioned previously, there are several ways SHDs can use social media. If utilized effectively, social media has the potential to improve the way public health agencies engage, interact and communicate with its various audiences. Specifically, social media are technologies that facilitate opportunities for engaging with the audience [1] and for creating and maintaining relationships [23]. If public health agencies can use social media to engage their audiences and create relationships, something that has previously been hindered by time and distance restrictions, then they are one step closer to establishing true community-based partnerships to address public health problems.

This study showed that, SHDs are not capitalizing on social media's interactive potential. Their one-way social media communication pattern is similar to the results of an analysis of politicians and government agency Twitter posts that revealed the most common purpose was a one-way sharing of public information [24]. Very few of the audience members were viewing the videos or photos. Using comments and likes as a proxy measure for reading posts, relatively few engaged in reading. A like indicates that a person has at least read a post or watched a video, and while there was a greater proportion of likes than comments received, it is only part of the engagement process. Research shows that if a person likes a product page, they are more likely to buy the brand, recommend the brand to others and share branded content [25]. However, liking the page does not result in purchasing the product. This may be true for public health as well. Liking a page or a post may not equal following behavioral recommendations or participation in public health programs.

There may be a few reasons why SHDs have limited social media interaction. The first may be that there is a mismatch between the content that is posted and audience preferences. SHDs are posting and tweeting about health topics and not about the agency. The health topics may be a reflection of the national health observances that were occurring during February and March, including American Heart Month, National Nutrition month, National School Breakfast Week, and Colorectal Cancer Awareness Month. If the audience is primarily other health professionals, general health content may generate fewer comments. If the audience is the general public, the content may be poorly developed or the topics may be of little interest. The majority of Facebook posts were auto feeds, meaning there was little thought 
given to matching the content with audience preferences for information. SHDs cannot assume that because they post content on a social media application that people will respond. It is important to communicate information in a way that reflects the audience preferences, stimulates response or discussion, and is tailored to the social media application.

Public health agencies use of social media is in the early adoption stages. Because social media use is becoming so pervasive, it seems prudent for SHDs to strategically consider how to use it to their advantage. To maximize social media's potential, public health agencies should develop a plan for incorporating it within their overall communication strategy. We recommend a framework posted by Bernoff and $\mathrm{Li}$ as a starting point [23]. The agency must identify what audience they are trying to reach, how that audience uses social media, what goals and objectives are most appropriate, and which social media applications fit best with the identified goals and objectives.

Some study limitations should be noted. First, there is not a universally accepted standard for which social media metrics measure presence, reach, or interactivity. Second, we identified the SHD as using social media if there was an institutional account as identified on the health department website home page. It is possible that individual programs or organizational units within a health department are using social media independent of a department-wide coordinated effort. Lastly, this was a cross-sectional study to establish a baseline of social media use by SHDs.

\section{Conclusions}

Most SHDs have recently begun to use at least one social media application. The most popular social media is Twitter despite the fact that only $13 \%$ of internet users have a Twitter account. The reach of social media is limited as evidenced by the low number of followers, page likes, and subscribers. Additionally, SHDs appear to be using social media as another channel to distribute information rather than creating conversations and engaging with the audience. If public health agencies are to use social media effectively they must develop a strategic communication plan that incorporates best practices for expanding reach and fostering interactivity and engagement.

\section{Acknowledgements \\ This study was funded by a grant from the sponsoring university.}

\section{Authors' contributions}

RT conceived of the study, participated its design and coordination, performed the statistical analysis, and drafted the manuscript. BLN conceived of the study, participated in its design and coordination, and helped draft the manuscript. AKS and SBV participated in the study design and coordination, collected the data, and helped draft the manuscript. All authors read and approved the final manuscript.
Competing interests

The authors declare that they have no competing interests.

Received: 29 October 2011 Accepted: 26 March 2012

Published: 26 March 2012

\section{References}

1. Safko J, Brake DK: The social media bible: Hoboken NJ: Wiley; 2009.

2. Stern J: Social media metrics: Hoboken NJ: Wiley; 2010.

3. Mangold WG, Faulds DJ: Social media: the new hybrid element of the promotion mix. Bus Horiz 2009, 52:357-365.

4. Vance K, Howe W, Dellavale RP: Social internet sites as a source of public health information. Dermatol Clin 2009, 27(2):133-136.

5. Sutton JN: Twittering Tennessee: distributed networks and collaboration following a technological disaster. Proceedings of the 7th International ISCRAM Conference: May 2010; Seattle, WA 2010 [http://www.iscram.org/ ISCRAM2010/Papers/113-Sutton.pdf].

6. Thackeray R, Hunter M: Use of empowering youth: use of technology in advocacy to affect social change. J Comput-Mediat Commun 2010, 15(4):577-591.

7. Frost JH, Massagli MP: Social uses of personal health information within PatientsLikeMe, an online patient community: what can happen when patients have access to one another's data. JIMR 2008, 10(3):e15.

8. Merchant RM, Elmer S, Lurie N: Integrating social media into emergencypreparedness efforts. N Eng J Med 2011, 365(4):289-291.

9. Chew C, Eysenbach G: Pandemics in the age of Twitter: content analysis of tweets during the 2009 H1N1 outbreak. PLoS One 2010, 5(11):e14118.

10. Radicati S: Email statistics report, 2011-2015.[http://www.radicati.com/? $p=7261]$.

11. Madden M, Zickuhr K: Social networking report.[http://www.pewinternet. org/Reports/2011/Social-Networking-Sites.aspx]

12. Technorati. [http://technorati.com/blogs/directory/].

13. Smith A: Twitter update 2011.[http://www.pewinternet.org/ /media//Files/ Reports/2011/Twitter\%20Update\%202011.pdf].

14. Barnes NG: The Fortune 500 and social media: a longitudinal study of blogging, Twitter and Facebook usage by America's largest companies. [http://www.umassd.edu/cmr/studiesandresearch/ bloggingtwitterandfacebookusage/].

15. Barnes NG: Social media usage among US top charities.[http://www. umassd.edu/cmr/studiesandresearch/socialmediatopcharities/].

16. Centers for Disease Control and Prevention: CDC eHealth metrics dashboard. [http://www.cdc.gov/metrics/socialmedia/index.html].

17. HealthyPeople.gov. [http://www.healthypeople.gov/2020/ topicsobjectives2020/objectiveslist.aspx?topicld=18]

18. National Public Health Information Coalition. [http://www.nphic.org/].

19. Third Annual Nonprofit Social Network Benchmark Report. [http:// nonprofitsocialnetworksurvey.com/download.php].

20. Thaker SI, Nowacki AS, Mehta NB: How U.S. hospitals use social media Ann Intern Med 2011, 154(10):707-708.

21. Moore $K: 71 \%$ of online adults now use video-sharing sites.[http:// pewinternet.org/Reports/2011/video-sharing-sites.aspx].

22. Lenhart A, Fox S: Twitter and status updating. Pew Internet project data memo.[http://www.pewinternet.org/ /media/Files/Reports/2009/PIP\% 20Twitter\%20Memo\%20FINAL.pdf].

23. Li C, Bernoff J: Groundswell Boston, MA: Harvard Business Press; 2008.

24. Waters RD, Williams JM: Squawking, tweeting, cooing, and hooting: analyzing the communication patterns of government agencies. Journal of Public Affairs 2011, doi:10.1002/pa.385.

25. Williamson DA: So you like my brand on Facebook. Now what?[http:// adage.com/article/digitalnext/brands-turn-likes-loyalty/227609/].

Pre-publication history

The pre-publication history for this paper can be accessed here: http://www.biomedcentral.com/1471-2458/12/242/prepub

doi:10.1186/1471-2458-12-242

Cite this article as: Thackeray et al:: Adoption and use of social media among public health departments. BMC Public Health 2012 12:242. 